\title{
Pengaruh BAP Dan NAA Terhadap Waktu Pertumbuhan Tanaman Kantong Semar (Nepenthes adrianii) Secara In-Vitro
}

\author{
Egi Nuryadin ${ }^{1}$ \\ ${ }^{1}$ Jurusan Pendidikan Biologi-FKIP, Universitas Siliwangi \\ J1. Siliwangi No. 24 Kota Tasikmalaya 46115 Jawa Barat \\ e-mail : egi.nuryadin@unsil.ac.id
}

\begin{abstract}
Abstrak
Nepenthes adrianii (Kantong Semar) merupakan tanaman endemik khas Gunung Slamet, termasuk da-lam Convention on International Trade of Endangered Species (CITES). Salah satu potensi Nepenthes adrianii sebagai pengendali serangga dan tanaman obat. Penelitian ini bertujuan untuk: 1) menentukan konsentrasi interaksi BAP dan NAA yang paling baik dan waktu munculnya untuk tunas, akar dan daun. Metode yang digunakan adalah metode eksperimental. Tahap munculnya tunas, akar dan daun menggunakan Rancangan Acak Lengkap (RAL) pola faktorial dengan 2 faktor. Faktor I adalah kon-sentrasi BAP yang terdiri dari 4 taraf yaitu $0 \mu \mathrm{M}, 5 \mu \mathrm{M}, 10 \mu \mathrm{M}$, dan $15 \mu \mathrm{M}$, Faktor II konsentrasi NAA yang terdiri dari 4 taraf yaitu yaitu $0 \mu \mathrm{M}, 0,5 \mu \mathrm{M}, 1 \mu \mathrm{M}$, dan 1,5 $\mu \mathrm{M}$. Hasil penelitian menunjukan bahwa perkecambahan biji tanaman Nepenthes adrianii dengan menggunakan media Vacin and Went (VW) dengan penambahan konsentrasi BAP $4 \mu \mathrm{M}$ dan perlakuan interaksi BAP $10 \mu \mathrm{M}$ dan NAA $0,5 \mu \mathrm{M}$ adalah waktu yang paling cepat dalam muncul tunas, akar dan daun.
\end{abstract}

Kata Kunci: BAP dan NAA, Kantong Semar, Nepenthes adrianii

\begin{abstract}
Nepenthes adrianii (a carnivorous plant) is an endemic carnivorous plant of Mount Slamet, which is listed the convention on international trade of endangered species (CITES). One potential posses Nepenthes adrianii the biological control of insects and plants medicine. The objectives of this study were to: 1) know concentration BAP and NAA optimal and know the time appear the emergence of shoots, roots and leaves. This research has been carried out experimentally. That stage of growth in bring up shoots, roots and leaves use a Completely Randomised Design on a two factors factorial pattern was us-ed. The first factor was BAP concentrations with 4 levels $0 \mu \mathrm{M}, 5 \mu \mathrm{M}, 10 \mu \mathrm{M}$, and $15 \mu \mathrm{M}$. The sec-ond factor was NAA concentration with 4 levels $0 \mu \mathrm{M}, 0,5 \mu \mathrm{M}, 1 \mu \mathrm{M}$, and 1,5 $\mu \mathrm{M}$. The research results showed germination of seeds in plants Nepenthes adrianii using media vacin and went (VW) with the addition of substance of a substance controller of growing BAP $4 \mu \mathrm{M}$ produce quite a lot germination and treatment $10 \mu \mathrm{M}$ BAP and $0,5 \mu \mathrm{M}$ NAA is the fastest in time to occur, appear leaves and appear roots.
\end{abstract}

Keywords: BAP and NAA, carnivorous plant, Nepenthes adrianii.

\section{PENDAHULUAN}

Nepenthes merupakan tanaman hias yang telah dikenal cukup lama di Indonesia. Nepenthes mempunyai keunikan dari penampilan yang eksotis karena dari ujung daun muncul kantong dengan corak serta warna beragam. Berbagai macam variasi kantong mulai dari bentuk, ukuran, motif dan warnanya menyebabkan tanaman ini disebut sebagai kantong semar dan masyarakat internasional menyebutnya sebagai the exotic pitcher plant atau pemanjat yang eksotis karena sifat pertumbuhan dialamnya dengan cara memanjat (Purwanto, 2007). Nepenthes juga mempunyai potensi sebagai pengendali hayati serangga dan tanaman obat (Mansur, 2006; Purwanto, 2007; dan Eilenberg et al., 2010).

Nepenthes adrianii merupakan salahsatu $\mathrm{Ne}$ penthes yang unik dan sudah termasuk tanaman yang langka, karena pertumbuhannya hanya dibeberapa tempat didataran tinggi, yaitu meru- pakan tanaman endemik khas Gunung Slamet (Egi, 2017). Di Indonesia Nepenthes adrianii termasuk kedalam tumbuhan yang dilindungi yang tertera dalam Peraturan Menteri Lingkungan Hidup dan Ke-hutanan Republik Indonesia Nomor P.20/MENLHK/SETJEN/KUM.1/6/ 2018 tentang jenis tumbuhan dan satwa yang dilindungi. Nepenthes adrianii termasuk dalam Convention on International Trade of Endangered Species (CITES) terdapat apendiks I (Tahun 2003) dan II yaitu tanaman ini tergolong hampir punah dan langka. Tanaman yang termuat di dalamnya merupakan jenis-jenis yang telah terancam punah (endangered) sehingga perdagangan internasional spesimen yang berasal dari habitat alam harus dikontrol dengan ketat dan hanya diperkenankan untuk kepentingan non komersial tertentu dengan izin khusus.

Besarnya potensi yang dimiliki tanaman ini, maka perlu upaya konservasi untuk mengem- 
bangkan dan melestarikannya. Penerapan bioteknologi dengan kultur in-vitro merupakan solusi yang tepat untuk melestarikan dan mengembangkan tanaman kantong semar, karena dalam teknik kultur in vitro ha-nya diperlukan sedikit bagian tanaman sebagai eksplan awal sehingga tidak mengganggu keberadaan tanaman dilapang, dan dalam waktu yang cukup singkat dapat diperoleh bibit tanaman (plantlet) yang unggul dalam jumlah yang relatif banyak. (Purwanto, 2007; Egi, 2017)

Penelitian kultur in vitro pada tanaman kantong semar masih jarang dilakukan. Terutama Nepenthes adrianii karena tanaman ini merupakan species baru dan belum dikenal oleh banyak orang, tanaman ini endemik khas Jawa Tengah yaitu di pegunungan slamet. Pe-nelitian terkait dengan kultur in vitro tanaman Nepenthes adrianii pernah dilakukan oleh Egi, 2017. Namun demikian upaya penyelamatan tanaman langka khususnya Nepenthes adrianii secara in vitro perlu dilakukan pe-nelitian berlanjut untuk menggali semua informasi serta potensi yang dimiliki.

\section{METODE PENELITIAN}

\section{A. Alat dan Bahan}

Alat yang digunakan dalam penelitian ini antara lain botol kultur, timbangan analitik, beaker glass, gelas ukur, botol Duran, Erlenmeyer, hot plate magnetic stirrer, $\mathrm{pH}$ meter, pipet, alumunium foil, autoklaf, Laminar Air Flow (LAF) Cabinet, bunsen, fridge, rak kultur, pinset, skalpel, cling film, kertas label, dan hand sprayer. Bahan-bahan yang digunakan yaitu biji Nepenthes adrianii, media vacin and went (VW), casein hydrolizate, sukrosa, agar, sterile destilled water (sdw), akuades, pupuk seedling cair PSA, al-kohol $70 \%$ dan $96 \%, \mathrm{HgCl}_{2} 0,2 \%$, zat peng-atur tumbuh 6-benzyl aminopurine (BAP) dan $\alpha$-naphthalenacetic acid ( $\alpha-\mathrm{NAA})$.

\section{B. Metode Penelitian}

Penelitian yang dilaksanakan merupakan penelitian eksperimental. Percobaan dilaku-kan dengan metode eksperimental dengan Rancangan Acak Lengkap (RAL) pola per-lakuan faktorial.

Faktor I adalah konsentrasi BAP yang ter-diri dari 4 taraf yaitu B1 $0 \mu \mathrm{M}, \mathrm{B} 25 \mu \mathrm{M}, \mathrm{B} 310 \mu \mathrm{M}$ dan B4 $15 \mu \mathrm{M}$. Faktor II adalah kon-sentrasi NAA yang terdiri dari 4 taraf yaitu $\mathrm{N} 10 \mu \mathrm{M}, \mathrm{N} 2$ $0,5 \mu \mathrm{M}, \mathrm{N} 31 \mu \mathrm{M}$ dan $\mathrm{N} 41,5 \mu \mathrm{M}$. Kombinasi perlakuan ada 16 perlakuan seperti pada tabel 1 berikut:

Tabel 1.

Kombinasi Perlakuan

Kombinasi Perlakuan
\begin{tabular}{|c|c|c|c|}
\hline $\mathrm{B}_{1} \mathrm{~N}_{1}$ & $\mathrm{~B}_{2} \mathrm{~N}_{1}$ & $\mathrm{~B}_{3} \mathrm{~N}_{1}$ & $\mathrm{~B}_{4} \mathrm{~N}_{1}$ \\
\hline $\mathrm{B}_{1} \mathrm{~N}_{2}$ & $\mathrm{~B}_{2} \mathrm{~N}_{2}$ & $\mathrm{~B}_{3} \mathrm{~N}_{2}$ & $\mathrm{~B}_{4} \mathrm{~N}_{2}$ \\
\hline $\mathrm{B}_{1} \mathrm{~N}_{3}$ & $\mathrm{~B}_{2} \mathrm{~N}_{3}$ & $\mathrm{~B}_{3} \mathrm{~N}_{3}$ & $\mathrm{~B}_{4} \mathrm{~N}_{3}$ \\
\hline $\mathrm{B}_{1} \mathrm{~N}_{4}$ & $\mathrm{~B}_{2} \mathrm{~N}_{4}$ & $\mathrm{~B}_{3} \mathrm{~N}_{4}$ & $\mathrm{~B}_{4} \mathrm{~N}_{4}$ \\
\hline
\end{tabular}

Masing-masing kombinasi perlakuan diulang 3 kali, sehingga diperoleh 48 unit percobaan.

\section{Variabel dan Parameter}

Variabel dan parameter yang diamati adalah waktu muncul tunas, waktu muncul akar dan waktu muncul daun dalam waktu 7 minggu setelah penanaman.

\section{Prosedur Kerja}

Tahap pertumbuhan Nepenthes adrianii ini terdiri dari Penyiapan biji, sterilisasi alat dan bahan, pembuatan media VW untuk perkecambahan, pembuatan larutan stok zat pengatur tumbuh, perkecambahan biji didalam laminar air flow, pembuatan media VW, pembuatan media perlakuan untuk multiplikasi tunas. Biji Nepenthes adrianii di kecambahkan dalam media VW dan menghasilkan tunas-tunas kecil. Tunas dari hasil perkecambahan kira-kira panjangnya $1 \mathrm{~cm}$ ditanam didalam botol, dan hasilnya disubkultur pada media terbaik.

\section{E. Analisis dan Interpretasi Data}

Analisis data dilakukan dengan analisis ragam (Anova: Analysis of Variance) dengan tingkat kepercayaan 95\% untuk mengetahui pengaruh perlakuan. Dan dilanjutkan dengan uji BNJ untuk mengetahui perbedaan antar perlakuan.

\section{HASIL DAN PEMBAHASAN}

Gambaran eksplan yang tumbuh pada ta-hap perkecambahan biji tersaji pada Gambar 1, sementara hasil analisis ragam dan uji beda nyata pengaruh perlakuan terhadap waktu muncul tunas, waktu muncul akar dan waktu muncul daun selama 7 minggu menunjukkan bahwa interaksi antara BAP dan NAA berpengaruh nyata pada waktu muncul daun dan tidak berpengaruh nyata pada waktu muncul tunas dan waktu muncul akar. Waktu muncul tunas dan akar sangat dipengaruhi oleh faktor mandiri BAP dan NAA. Rata-rata dari hasil keseluruhan didapatkan perlakuan $\mathrm{B}_{3} \mathrm{~N}_{2}(10 \mu \mathrm{M}$ BAP dan $0,5 \mu \mathrm{M}$ NAA $)$ merupakan perlakuan paling cepat dalam waktu muncul tunas, muncul daun dan muncul akar. 


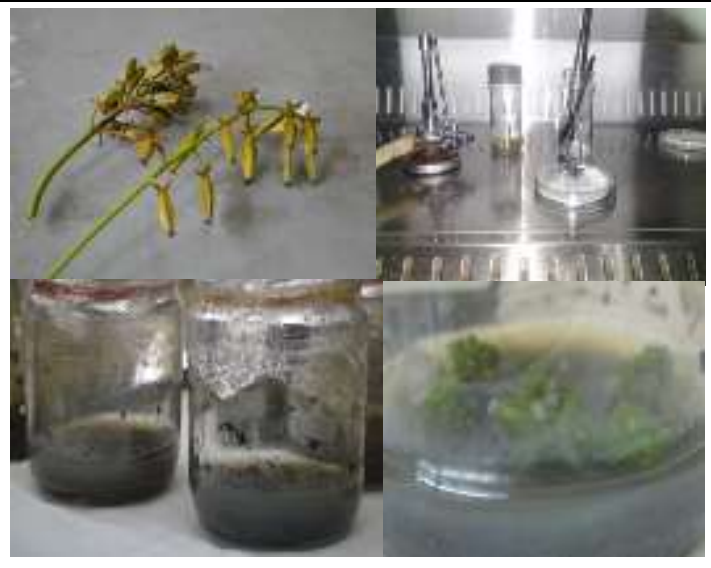

Gambar 1. Biji Nepenthes adrianii yang digunakan sebagai eksplan dan hasil perkecambahannya

\section{A. Perkecambahan Biji}

Perkecambahan biji Nepenthes adrianii pada media Vacin and Went (VW) memberikan hasil yang bagus, dilihat dari pertumbuhan perkecambahan biji tersebut (gambar 1). Perkecambahan biji Nepenthes adrianii selama 10 minggu sampai menghasilkan tunas-tunas kecil yang berukuran $\pm 1 \mathrm{~cm}$. Tunas-tunas kecil ini digunakan dalam peneliti-an untuk multiplikasi tunas. Pertumbuhan dan perkembangan biji dipengaruhi oleh beberapa faktor diantaranya lingkungan, nutrient, gen dan hormon. Hormon merupakan senyawa yang dihasilkan tanaman secara endogen, dalam jumlah sedikit dapat meningkatkan ataupun menghambat pertumbuhan tanaman (LIPI, 2012; dan Lestari et al., 2011).

Dalam penelitian ini untuk perkecambahan biji pada tanaman Nepenthes adrianii menggunakan zat pengatur tumbuh BAP $4 \mu \mathrm{M}$ dan menghasilkan perkecambahan yang cu-kup banyak, menurut penelitian sebelumnya untuk perkecambahan biji Nepenthes meng-gunakan media $1 / 2$ MS dengan penambahan media BAP sebanyak $2 \mathrm{mg} / \mathrm{L}$ dan $0,2 \mathrm{mg} / \mathrm{L} 3$ berkecambah lebih banyak daripada media perlakuan seperti media $1 / 2$ MS dengan penambahan zat pengatur tumbuh NAA $0,5 \mathrm{mg} / \mathrm{L}$ dan $1 \mathrm{mg} / \mathrm{L}$ tidak ada biji yang berkecambah sampai akhir pengamatan (LIPI, 2012). Penelitian tentang pengaruh jenis media pada perkecambahan benih dan pengaruh dari BAP pada propagasi masal Nepenthes mirabilis, hasil penelitian tersebut menun-jukkan bahwa penggunaan media VW dengan penambahan zat pengatur tumbuh menghasilkan rata-rata perkecambah-an biji Nepenthes mirabilis lebih baik dari-pada media $1 / 2$ MS. (Jala dan Anchalee, 2012).
B. Pengaruh Interaksi BAP dan NAA terhadap Rata-rata Waktu Muncul Tunas, Waktu Muncul Daun dan Waktu Muncul Akar

Hasil analisis ragam dan uji beda nyata pengaruh perlakuan terhadap rata-rata waktu muncul tunas, waktu muncul daun dan waktu muncul akar pada tahap multiplikasi tunas tersaji pada Tabel 2. Data pada Tabel 2 men-unjukkan bahwa interaksi antara BAP dan NAA berpengaruh nyata pada waktu muncul daun dan tidak berpengaruh nyata pada parameter waktu muncul tunas dan waktu muncul akar. Waktu muncul tunas dan akar sangat dipengaruhi oleh faktor mandiri BAP dan NAA. Lebih lanjut, data pada Tabel 2 juga menunjukkan bahwa perlakuan $\mathrm{B}_{3} \mathrm{~N}_{2}(10 \mu \mathrm{M}$ BAP dan $0,5 \mu \mathrm{M}$ NAA) merupakan perlakuan paling cepat dalam waktu muncul tunas, mun-cul daun dan muncul akar.

Tabel 2.

Interaksi BAP dan NAA terhadap Rata-rata Waktu Muncul Tunas, Waktu Muncul Daun dan Waktu Muncul Akar Selama 7 Minggu

\begin{tabular}{|c|c|c|c|}
\hline Data & $\begin{array}{c}\text { Waktu Muncul } \\
\text { Tunas }\end{array}$ & $\begin{array}{c}\text { Waktu Mun- } \\
\text { cul Daun }\end{array}$ & $\begin{array}{c}\text { Waktu Muncul } \\
\text { Akar } \\
\end{array}$ \\
\hline F hit B & 1.66 & 1.36 & $5.02 * *$ \\
\hline $\mathrm{F}$ tab $5 \%$ & 2.90 & 2.90 & 2.90 \\
\hline $\mathrm{F}$ tab $1 \%$ & 4.46 & 4.46 & 4.46 \\
\hline B1 & 12.2 & 9.9 & $13.2 \mathrm{ab}$ \\
\hline B2 & 10.5 & 8.8 & $14.1 \mathrm{a}$ \\
\hline B3 & 9.8 & 9.2 & $9.2 \mathrm{~b}$ \\
\hline B4 & 12.7 & 10.8 & $14.4 \mathrm{a}$ \\
\hline F hit $\mathrm{N}$ & $18.69 * *$ & 1.57 & $13.94 * *$ \\
\hline $\mathrm{F}$ tab $5 \%$ & 2.90 & 2.90 & 2.90 \\
\hline $\mathrm{F}$ tab $1 \%$ & 4.46 & 4.46 & 4.46 \\
\hline N1 & $17.8 \mathrm{a}$ & 10.8 & $18.6 \mathrm{a}$ \\
\hline N2 & $8.3 \mathrm{~b}$ & 8.7 & $9.7 \mathrm{~b}$ \\
\hline N3 & $8.1 \mathrm{~b}$ & 10.1 & $10.6 \mathrm{~b}$ \\
\hline N4 & $11.0 \mathrm{~b}$ & 9.1 & $12.0 \mathrm{~b}$ \\
\hline $\begin{array}{l}\text { F hit } \\
\text { BXN }\end{array}$ & 1.30 & $2.29 *$ & 2.19 \\
\hline $\mathrm{F}$ tab $5 \%$ & 2.19 & 2.19 & 2.19 \\
\hline $\mathrm{F}$ tab $1 \%$ & 3.02 & 3.02 & 3.02 \\
\hline B1N1 & 16.7 & $9.3 \mathrm{ab}$ & 20.3 \\
\hline $\mathrm{B} 1 \mathrm{~N} 2$ & 9.7 & $9.3 \mathrm{ab}$ & 10.3 \\
\hline $\mathrm{B} 1 \mathrm{~N} 3$ & 8.7 & $8.7 \mathrm{ab}$ & 8.7 \\
\hline B1N4 & 13.7 & $12.3 \mathrm{ab}$ & 13.3 \\
\hline $\mathrm{B} 2 \mathrm{~N} 1$ & 15.3 & $8.7 \mathrm{ab}$ & 21.0 \\
\hline $\mathrm{B} 2 \mathrm{~N} 2$ & 8.7 & $9.3 \mathrm{ab}$ & 10.0 \\
\hline $\mathrm{B} 2 \mathrm{~N} 3$ & 10.0 & $9.7 \mathrm{ab}$ & 16.3 \\
\hline $\mathrm{B} 2 \mathrm{~N} 4$ & 8.0 & $7.3 \mathrm{ab}$ & 9.0 \\
\hline
\end{tabular}




\begin{tabular}{cccc}
\hline Data & $\begin{array}{c}\text { Waktu Muncul } \\
\text { Tunas }\end{array}$ & $\begin{array}{c}\text { Waktu Mun- } \\
\text { cul Daun }\end{array}$ & $\begin{array}{c}\text { Waktu Muncul } \\
\text { Akar }\end{array}$ \\
\hline B3N1 & 19.0 & $10.0 \mathrm{ab}$ & 11.3 \\
B3N2 & 6.3 & $7.0 \mathrm{~b}$ & 7.7 \\
B3N3 & 6.7 & $12.7 \mathrm{ab}$ & 8.7 \\
B3N4 & 7.3 & $7.0 \mathrm{~b}$ & 9.0 \\
B4N1 & 20.0 & $15.0 \mathrm{a}$ & 21.7 \\
B4N2 & 8.7 & $9.0 \mathrm{ab}$ & 10.7 \\
B4N3 & 7.0 & $9.3 \mathrm{ab}$ & 8.7 \\
B4N4 & 15.0 & $9.7 \mathrm{ab}$ & 16.7 \\
\hline
\end{tabular}

Angka yang diikuti huruf yang sama tidak berbeda nyata pada BNJ $5 \%$

\section{Waktu Muncul Tunas}

Hasil penelitian menunjukkan bahwa waktu muncul tunas Nepenthes adrianii tidak dipengaruhi oleh interaksi BAP dan NAA (Tabel 2), akan tetapi dipengaruhi oleh BAP atau NAA yang diberikan secara mandiri. Hasil uji regresi pengaruh konsentrasi NAA pada waktu muncul tunas diperoleh persamaan regresi: $\mathrm{Y}=17.45$ $22.6 \mathrm{X}+12.333333 \mathrm{X}^{\wedge} 2 \mathrm{R}^{\wedge} 2=51.94 \%$ dengan hasil perhitungan konsentrasi optimum BAP diperoleh angka 9,70 $\mu \mathrm{M}$ BAP. Hal ini sejalan dengan penelitian Alitalia, et al (2008) bahwa waktu inisiasi tunas Nepenthes tidak dipengaruhi interaksi BAP dan NAA melainkan dipengaruhi BAP dan NAA secara mandiri. Hal ini dimungkinkan terdapat hormon endogen yang cukup kuat pada tanaman nepenthes, sehingga waktu untuk muncul tunas diperlukan hormon eksogen secara mandiri.

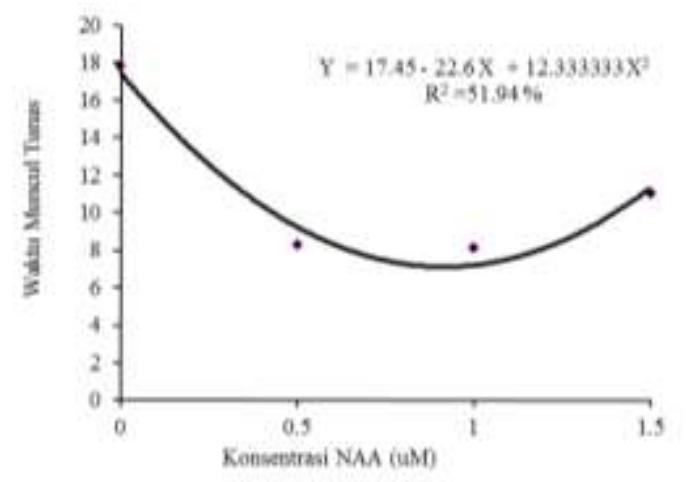

Gambar 2. Hasil uji regresi pengaruh NAA pada waktu muncul tunas Nepenthes adrianii

\section{Waktu Muncul Daun}

Hasil penelitian menunjukkan bahwa waktu muncul daun Nepenthes adrianii dipengaruhi oleh interaksi BAP dan NAA (Tabel 2). Data pada Tabel tersebut juga menunjukkan bahwa perlakuan $\mathrm{B}_{3} \mathrm{~N}_{2}(10 \mu \mathrm{M}$ BAP dan 0,5 $\mu \mathrm{M}$ NAA $)$

dan $\mathrm{B}_{3} \mathrm{~N}_{4}(10 \mu \mathrm{M}$ BAP dan 1,5 $\mu \mathrm{M}$ NAA $)$ memiliki rata-rata waktu muncul tunas tercepat yaitu 7,0. Hasil uji regresi kuadrater BAP pada taraf $\mathrm{N}_{2}$ didapatkan persamaan regresi $\mathrm{Y}=9.1666667$ - $0.06666667 \times \mathrm{R}^{\wedge} 2=2.66 \%$ dan diperoleh konsentrasi optimal 8,65 $\mu \mathrm{M}$ BAP. Hal ini diduga dengan pemberian konsentrasi yang optimal dengan NAA konsentrasi rendah akan memberikan waktu muncul daun lebih cepat.

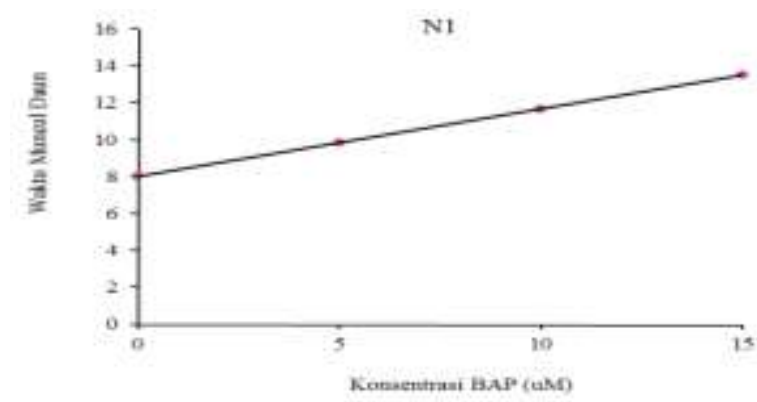

Gambar 3. Hasil uji regresi pengaruh BAP pada waktu muncul daun Nepenthes adrianii

\section{a. Waktu Muncul Akar}

Hasil penelitian menunjukkan bahwa waktu muncul akar Nepenthes adrianii tidak dipengaruhi oleh interaksi BAP dan NAA (Tabel 2), akan tetapi dipengaruhi oleh BAP atau NAA yang diberikan secara mandiri. Hal ini diduga adanya hormon endogen cukup kuat yang terdapat pada tanaman Nepenthes sehingga dengan pemberian BAP dan NAA secara mandiri akan menstimulus untuk tumbuhnya akar. Hasil uji regresi pengaruh konsentrasi BAP pada waktu muncul akar diperoleh persamaan regresi: $\mathrm{Y}=$ $13.166667+1.8333333 X-0.43666667 X^{\wedge} 2+$ $0.02133333 \mathrm{X}^{\wedge} 3 \quad \mathrm{R}^{\wedge} 2=13.87 \%$. Hasil uji regresi pengaruh konsentrasi NAA diperoleh $\mathrm{Y}=$ $18.116667-19.266667 \mathrm{X}+10.333333 \mathrm{X}^{\wedge} 2$ $\mathrm{R}^{\wedge} 2=35.08 \%$.

Menurut Sukawan (2000), pembentukan akar selain dipengaruhi oleh pemberian auksin eksogen juga dipengaruhi oleh perbedaan genetik yang disebabkan oleh eksplan yang digunakan dan kandungan sitokinin endogennya. Hal yang sama juga dikemukakan oleh Alitalia, et al (2008) Bahwa pada umumnya akar akan terbentuk apabila nisbah konsentrasi sitokinin dan auksin rendah. Dalam hal ini pemakaian BAP dan NAA dengan konsentrasi rendah bisa memicu tumbuhnya akar. 


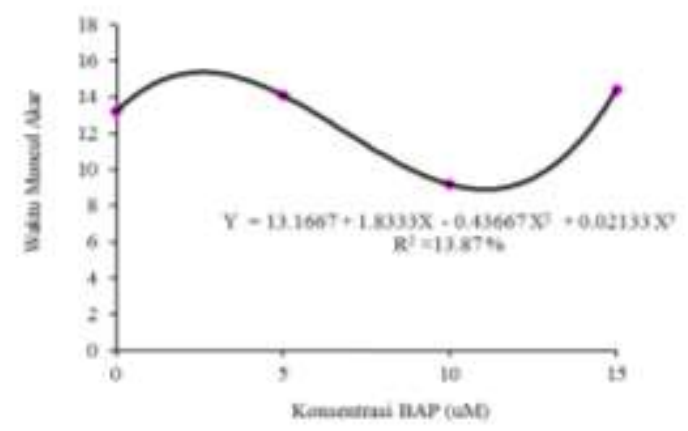

Gambar 4. Hasil uji regresi pengaruh BAP pada waktu muncul akar Nepenthes adrianii

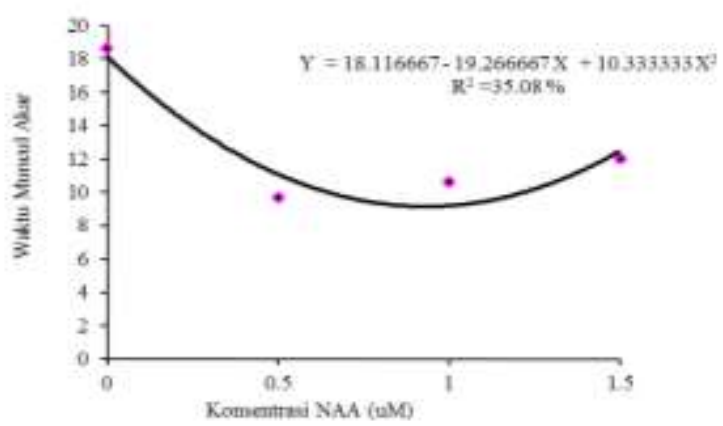

Gambar 5. Hasil uji regresi pengaruh NAA pada waktu muncul akar Nepenthes adrianii.

\section{KESIMPULAN}

Berdasarkan hasil penelitian dan pembahasan maka didapatkan perlakuan $\mathrm{B}_{3} \mathrm{~N}_{2}$ $(10 \mu \mathrm{M}$ BAP dan $0,5 \mu \mathrm{M}$ NAA) merupakan perlakuan paling cepat dalam waktu muncul tunas, muncul daun dan muncul akar. Waktu muncul tunas diperoleh konsentrasi yang optimum dengan penambahan BAP secara mandiri diperoleh angka $9,70 \mu \mathrm{M}$, waktu muncul akar dipengaruhi oleh pemberian BAP dan NAA secara mandiri dan waktu muncul daun dipengaruhi adanya interaksi BAP dan NAA dan diperoleh konsentrasi optimal 8,65 $\mu \mathrm{M}$ BAP ditambah 0,5 $\mu$ M NAA.

Perkecambahan biji Nepenthes adrianii sangat baik menggunkan media Vacin and went (VW). Untuk mempercepat biji berkecambah bisa meggunakan zat pengatur tumbuh seperti BAP atau GA3 dengan konsentrasi yang sedikit. Untuk mendapatkan pertumbuhan yang optimal pada Nepenthes adrianii dengan menambahkan $10 \mu \mathrm{M}$ BAP dan $0,5 \mu \mathrm{M}$ NAA.

\section{DAFTAR RUJUKAN}

Alitalia, Y. (2008). Pengaruh Pemberian BAP dan NAA Terhadap Pertumbuhan dan Perkembangan Tunas Mikro Kantong Semar (Nepenthes mirabilis) secara In vitro.
(Skripsi). Bogor: Institut Pertanian Bogor.

Egi, N. 2017. Pengaruh Zat Pengatur Tumbuh Terhadap Multiplikasi Tunas dan Bahan Penyangga pada Pembentukan Plantlet Kantong Semar Adrianii (Nepenthes adrianii) dengan Kultur In Vitro. Jurnal Bioeksperimen, 3 (2): 31-44.

Eilenberg, H., Cohen, S.P., Rahamin, Y., Sionov, E., Segal, E., Carmeli. S., Zilberstein, A. 2010. Induced production of antifungal naphtoquinones in the pitchers of the carnivorous plant Nepenthes khasiana. J. Experimental Botany, 61:911-922.

Jala, Anchalee. 2012. Types of Media for Seeds Germination and Effect of BA on Mass Propagation of Nepenthes mirabilis Druce. Biotechnology Department, Faculty of Science and Technology, Thammasat University, THAILAND, 12(1):21.

Lestari, E.G, 2011. Peranan Zat Pengatur Tumbuh dalam Perbanyakan Tanaman melalui Kultur Jaringan. Jurnal AgroBiogen, 7(1):6368.

LIPI. 2012. Mengenal Kantong Semar adrianii. Bogor: Kanisius.

Mansur, M. 2006. Nepenthes, Kantong Semar yang Unik. Jakarta: Penebar Swadaya.

Purwanto, A. W. 2007. Budi Daya Ex-Situ Nepenthes Kantong Semar nan Eksotis. Yogyakarta: Kanisius.

Sukawan, I. K. 2000. Perbanyakan Tanaman Nenas Varietas Veriegata (Ananas comosus "veriegatus") secara In Vitro. (Skripsi). Bogor: Institut Pertanian Bogor. Bogor. 